\title{
FUNGSI RENCANA TATA RUANG WILAYAH PROVINSI SEBAGAI INSTRUMEN HUKUM PENGENDALIAN PEMANFAATAN RUANG KAWASAN HUTAN
}

\author{
THE FUNCTION OF PROVINCE AREA SPATIAL PLAN AS A LEGAL INSTRUMENTS FOR \\ THE CONTROL OF UTILIZATION OF FOREST AREA SPACE
}

Iskandarb

\begin{abstract}
ABSTRAK
$\mathrm{P}$ elanggaran hukum terhadap kebijakan tata ruang kawasan hutan provinsi masih terus terjadi. Kondisi ini menunjukkan bahwa Rencana Tata Ruang Wilayah Provinsi (RTRWP) sebagai instrumen hukum pengendalian pemanfaatan ruang kawasan hutan tidak berfungsi secara optimal. Tujuan dari kajian ini yaitu untuk mendeskripsikan fungsi RTRWP, malfungsi RTRWP dan solusinya. Metode kajian bersifat yuridis normatif, mengkaji bahan hukum primer dan sekunder. Analisis dilakukan secara yuridis kualitatif. Hasil kajian menunjukkan bahwa RTRWP merupakan instrumen hukum pengendalian pemanfaatan ruang kawasan hutan, sehingga pengawasan dan penerapan sanksi atas pelanggaran harus dilakukan. Penyebab fungsi RTRWP tidak optimal berkait dengan substansi ruang kawasan hutan dan implementasinya. Solusi mengatasi agar RTRWP berfungsi sebagai instrumen hukum pengendalian yaitu melakukan inventarisasi kondisi objektif eksisting kawasan hutan, penyelesaian tata batas, pemetaan dan penetapan kawasan hutan, pengawasan melalui citra satelit, membangun pola kemitraan, tertib dalam perizinan, meningkatkan kapasitas dan integritas aparatur penegak hukum, dan pembentukan Lembaga Pencegahan dan Pemberantasan Perusakan Hutan.
\end{abstract}

Kata kunci: fungsi; instrumen hukum; kawasan hutan; RTRWP.

\begin{abstract}
I egal violations of the provincial forest area spatial policy has still happened. This condition indicates that the L provincial spatial plan (RTRWP) as a legal instrument controlling the forest space utilization does not function optimally. The purpose of this study is to describe the function of RTRWP, RTRWP malfunction, and its solution. This method of study is normative juridical, reviewing primary and secondary legal materials. The analysis was done qualitatively juridical. The results of the study show that RTRWP is a legal instrument control of forest area utilization, so that supervision and application of sanctions for violations must be done. The cause of the RTRWP function is not optimally associated with the substance of the forest area and its implementation. The solution to overcome the RTRWP function as a controlling legal instrument is to make an inventory of objective conditions existing forest areas, resolve boundaries, mapping and determination of forest areas, monitor through satellite imagery, build a pattern of partnership, orderly in licensing, increase the capacity and integrity of law enforcement officials, and the establishment of Institute for the Prevention and Eradication of Forest Destruction.
\end{abstract}

Keywords: functions; forest areas; legal instruments; RTRWP.

\footnotetext{
a Artikel disampaikan pada Seminar Nasional Fakultas Hukum Universitas Bengkulu, 3 Oktober 2019.

b Fakultas Hukum Universitas Bengkulu, Jl. WR Supratman, Kandang Limun Bengkulu, Bengkulu 38373, email: suttaniskandar@yahoo.com.
} 


\section{PENDAHULUAN}

S alah satu instrumen penting dalam penyelenggaraan pemerintahan dan pembangunan daerah yaitu menyusun Rencana Tata Ruang Wilayah Provinsi (RTRWP). Fungsi RTRWP yaitu menjadi dasar dalam penetapan arahan pengendalian pemanfaatan ruang wilayah daerah, sehingga RTRWP yang telah ditetapkan dengan peraturan daerah menjadi instrumen hukum dalam upaya pengendalian pemanfaatan ruang, bukan instrumen untuk mendatangkan pendapatan ekonomi bagi daerah, sehingga RTRWP akan berubah menjadi "rencana tata uang daerah",, bila demikian maka akan terjadi malfungsi RTRWP.

Berkenaan dengan penyusunan RTRWP, tentu akan berkait dengan penataan ruang kawasan hutan², atau tata ruang kawasan hutan merupakan bagian muatan dari RTRWP, sehingga kebijakan penetapan dalam RTRWP akan memberikan implikasi luas terhadap keberadaan ruang kawasan hutan di daerah. Penataan ruang kawasan hutan, bukanlah proses membagi-bagi kawasan hutan untuk berbagai kepentingan, melainkan suatu upaya untuk melindungi dan mengelola kawasan hutan agar kawasan hutan yang telah ditetapkan dapat berfungsi mencegah bencana lingkungan bagi manusia dan lingkungan hidup. Secara substansi RTRWP harus lebih ditekankan pada kelestarian dan keberlanjutan fungsi lingkungan hidup, serta tidak memberikan ruang pada pemanfaatan yang dapat merusak kawasan hutan.

Pada wilayah yang telah ditetapkan sebagai kawasan dengan fungsi lindung dan konservasi dalam RTRWP, pada dasarnya tidak boleh ada aktivitas manusia yang dapat mengganggu atau mengancam eksistensi kawasan hutan dimaksud. Dengan memahami pentingnya fungsi RTRWP sebagai instrumen pengendalian pemanfaatan ruang termasuk ruang kawasan hutan, maka dalam penyusunan RTRWP harus dilakukan dengan sebaik mungkin, sesuai dengan kondisi objektif wilayah suatu daerah berdasarkan data yang dapat dipertanggungjawabkan keabsahannya, bukan data berdasarkan estimasi atau hasil rekayasa.

Menyusun RTRWP juga tidak boleh dibuat sekadar sesuai selera penyusun dan keinginan pemerintah daerah, tetapi harus didasarkan pada perencanaan objektif yang akan diwujudkan berdasarkan hasil kajian. Proses penataan ruang kawasan hutan yang wajib dilakukan yaitu penetapan kawasan hutan lindung yang berfungsi sebagai resapan air hujan,

\footnotetext{
1 Bandingkan dengan Epi Syahadat, Subarudi, 2012, “Permasalahan Penataan Ruang Kawasan Hutan Dalam Rangka Revisi Rencana Tata Ruang Wilayah Provinsi (Problems On Forest And Land Use System For Revision Of Provincial Land Use System)", Jurnal Analisis Kebijakan Kehutanan, Vol. 9 No. 2, Agustus, hlm. 135.

2 Kawasan hutan adalah wilayah tertentu yang ditunjuk dan/atau ditetapkan oleh Pemerintah untuk dipertahankan keberadaannya sebagai hutan tetap. Lihat Iskandar, et.al., 2011, Kebijakan Perubahan Kawasan Hutan, Dalam Pengelolaan Berkelanjutan, Bandung: Unpad Press, hlm. 14.
} 
Fungsi Rencana Tata Ruang Wilayah Provinsi Sebagai Instrumen Hukum Pengendalian Pemanfaatan Ruang

mengendalikan air banjir, mengendalikan erosi tanah dan tanah longsor, serta menghindari kekeringan pada daerah hilir. ${ }^{3}$

Permasalahan yang terjadi dalam pemanfaatan ruang kawasan hutan, diantaranya mengenai kepemilikan, tumpang tindih batas wilayah administratif, tata batas kawasan hutan, status perizinan dan aktivitas tambang 4 dan kebun di dalam kawasan hutan serta isu berapa luas hutan yang akan dipertahankan. ${ }^{5}$ Terjadinya permasalahan tersebut karena RTRWP belum berfungsi secara optimal dalam menyelaraskan, mensinkronkan, dan memadukan berbagai rencana dan program sektoral; Belum adanya keterbukaan dalam menempatkan kepentingan sektoral, daerah, dan kepentingan masyarakat; Penyusunan RTRWP yang tidak didasarkan atas data luasan kawasan hutan yang obyektif; Inkonsistensi dalam pelaksanaan kebijakan RTRWP, sehingga berdampak pada lemahnya fungsi RTRWP sebagai instrumen hukum pengendalian pemanfaatan ruang kawasan hutan. ${ }^{6}$

Kondisi demikian ini menjadi paradoks, karena realitas di lapangan pelaksanaan kebijakan yang telah ditetapkan dalam RTRWP tidak konsisten, kemudian RTRWP "dianggap" sudah tidak sesuai lagi dengan tuntutan dinamika pembangunan, sehingga RTRWP perlu dilakukan evaluasi dan peninjauan kembali (PK), dengan maksud menghasilkan rekomendasi "perlu" dilakukan revisi/perubahan RTRWP. Revisi atau perubahan tersebut memang dimungkinkan untuk dilakukan, karena secara normatif telah diatur dalam Pasal 23 Ayat (3) dan (4) UU No. 26 Tahun 2007 tentang Penataan Ruang (UUTR) dan peraturan pelaksanaannya. RTRWP disusun untuk perencanaan 20 (dua puluh) tahunan, meski dimungkinkan dilakukan perubahan pada kurun waktu 5 (lima) tahunan, tapi haruslah dipahami bahwa perubahan RTRWP dimaksud bukan untuk dijadikan sarana "pemutihan"/legalisasi atas penyimpangan/pelanggaran yang dilakukan oleh para pemangku kepentingan, baik pemerintah, pemerintah daerah, pelaku usaha ataupun

\footnotetext{
3 Lihat Transtoto Handadhari, 2016, Tata Ruang dan Bencana, Majalah Gatra, hlm. 60-61, tanggal 4 Maret, diakses pada https://www.atrbpn.go.id/Berita/Berita-Pertanahan/tata-ruang-dan-bencana-alam-61881, 8 September 2019.

4 Pasal 134 ayat (2) UU No. 4 Tahun 2009 tentang Minerba, kegiatan usaha pertambangan tidak dapat dilaksanakan pada tempat yang dilarang untuk melakukan kegiatan usaha pertambangan sebelum memperoleh izin dari instansi Pemerintah sesuai dengan ketentuan peraturan perundang-undangan. Lihat juga Pasal 50 ayat (3) huruf g jo. Pasal 38 ayat (3) UU No. 41 Tahun 1999 tentang Kehutanan.

5 Luas hutan minimal yang dicantumkan pada UU Kehutanan yaitu sebesar 30\%. Penetapan angka 30\% tidak memiliki dasar ilmiah, namun dijadikan patokan luas "minimal" hutan yang harus dipertahankan, selebihnya dipaksakan untuk tujuan konversi hutan menjadi peruntukan lain tanpa mempertimbangkan perlindungan wilayah dari bencana alam dan kepentingan lingkungan hidup. Angka luasan hutan minimal 30\% tersebut harus dikaji kembali untuk memperoleh perhitungan yang lebih riil dan ilmiah di setiap tipe wilayah daerah aliran sungai (DAS), wilayah provinsi, wilayah kabupaten, dan wilayah pulau. Lihat Transtoto Handadhari, Ibid.

6 Bandingkan dengan Suwitno Y. Imran, 2013, “Fungsi Tata Ruang Dalam Menjaga Kelestarian Lingkungan Hidup Kota Gorontalo", Jurnal Dinamika Hukum, Vol. 13 No. 3 September, hlm. 457-458.
} 
masyarakat. Artinya, penyimpangan dalam pelaksanaan RTRWP terkait dengan pemanfaatan ruang kawasan hutan tetap merupakan perbuatan melanggar hukum, dan konsekuensi atas pelanggaran tersebut maka hukum harus ditegakkan, pelaku pelanggaran harus dikenakan sanksi.

\section{IDENTIFIKASI MASALAH}

$\mathrm{M}$ encermati fakta hukum RTRWP khususnya dalam pemanfaatan ruang kawasan hutan sebagaimana terurai di atas, Isu hukum yang dikaji yaitu: bagaimana fungsi RTRWP sebagai instrumen hukum pengendalian pemanfaatan ruang kawasan hutan, apa yang menjadi faktor penyebab terjadinya malfungsi RTRWP sebagai instrumen hukum pengendalian pemanfaatan ruang kawasan hutan, bagaimana solusi agar RTRWP dapat berfungsi secara optimal sebagai instrumen hukum pengendalian pemanfaatan ruang kawasan hutan.

\section{TUJUAN PENELITIAN}

ejalan dengan permasalahan, maka tujuan dari kajian ini yaitu untuk menjelaskan fungsi RTRWP sebagai instrumen hukum pengendalian dalam pemanfaatan ruang kawasan hutan, menganalisis faktor penyebab terjadinya malfungsi RTRWP sebagai instrumen hukum, dan menemukan solusi agar RTRWP dapat berfungsi secara optimal sebagai instrumen hukum pengendalian pemanfaatan ruang kawasan hutan.

\section{METODE PENELITIAN}

etode yang digunakan dalam kajian ini bersifat yuridis normatif. Pengumpulan bahan
hukum primer, sekunder, dan tersier yang terkait dengan RTRWP bidang kehutanan dilakukan melalui studi kepustakaan. Terhadap bahan hukum yang diperoleh dilakukan pengolahan dan analisis. Pengolahan bahan hukum dengan melakukan verifikasi dan klasifikasi, sedangkan analisis dilakukan secara yuridis kualitatif yaitu dengan melakukan interpretasi secara autentik (resmi/ sahih), sistematis (dogmatis), dan sosiologis (teleologis). Hasil analisis dideskripsikan secara sistematis sesuai dengan pokok bahasan dan ditarik kesimpulan sebagai argumentasi jawaban atas isu hukum yang dikaji. 
Fungsi Rencana Tata Ruang Wilayah Provinsi Sebagai Instrumen Hukum Pengendalian Pemanfaatan Ruang

\section{PEMBAHASAN}

Fungsi RTRWP sebagai Instrumen Hukum Pengendalian Pemanfaatan Ruang Kawasan Hutan

1. Fungsi RTRWP Sebagai Instrumen Pengendalian Pemanfaatan Ruang

$\mathrm{R}$ TRWP memuat tujuan, kebijakan, dan strategi penataan ruang wilayah provinsi, rencana struktur ruang wilayah provinsi, rencana pola ruang wilayah provinsi, penetapan kawasan strategis provinsi, arahan pemanfaatan ruang wilayah provinsi yang berisi indikasi program utama jangka menengah lima tahunan, dan arahan pengendalian pemanfaatan ruang wilayah provinsi yang berisi indikasi arahan peraturan zonasi, arahan perizinan, arahan insentif dan disinsentif, serta arahan sanksi. Jangka waktu RTRWP 20 (dua puluh) tahun, dan dapat ditinjau kembali 1 (satu) kali dalam 5 (lima) tahun. Dalam kondisi lingkungan strategis tertentu yang berkaitan dengan bencana alam skala besar yang ditetapkan dengan peraturan perundang-undangan dan/atau perubahan batas teritorial negara dan/atau wilayah provinsi yang ditetapkan dengan Undang-Undang, RTRWP dapat ditinjau kembali lebih dari 1 (satu) kali dalam 5 (lima) tahun.

RTRWP ditetapkan dengan peraturan daerah (Perda) provinsi. Jika telah ditetapkan dengan instrumen hukum Perda, maka RTRWP tersebut menjadi peraturan perundangundangan daerah (produk hukum daerah) yang harus dipatuhi dan ditegakkan. Dengan demikian RTRWP berfungsi sebagai instrumen hukum dalam pengendalian pemanfaatan ruang. Instrumen pengendalian pemanfaatan ruang dimaksud terdiri atas: ketentuan umum peraturan zonasi, arahan perizinan, arahan pemberian insentif dan disinsentif serta arahan pengenaan sanksi.

Ketentuan umum peraturan zonasi memiliki beberapa fungsi, diantaranya yaitu sebagai instrumen pengendalian pemanfaatan ruang, memuat ketentuan tentang kegiatan-kegiatan yang diperkenankan, yang tidak diperkenankan, yang diperkenankan bersyarat atau diperkenankan secara terbatas untuk berada pada suatu pola pemanfaatan ruang tertentu. Zonasi untuk Kawasan Lindung terdiri atas: Kawasan hutan lindung; Kawasan yang dapat memberikan perlindungan kepada kawasan bawahannya; Kawasan perlindungan setempat; Kawasan suaka alam, pelestarian alam dan cagar budaya; Kawasan rawan bencana alam; Kawasan Lindung geologi; dan Kawasan Lindung lainnya. Arahan perizinan pemanfaatan ruang merupakan acuan bagi penertiban pemanfaatan ruang pada tingkat operasional, yaitu yang diberikan pada pemanfatan ruang di tingkat kabupaten/kota dan kecamatan, seperti Izin Prinsip, Izin Mendirikan Bangunan (IMB), dan Izin Tempat Usaha. Semua jenis perizinan 
pemanfaatan ruang pada prinsipnya harus diintegrasikan dan sesuai dengan tujuan penataan ruang provinsi.

Instrumen pengendalian lain yaitu pemberian insentif dan disinsentif. Pemberian insentif diberlakukan pada pemanfaatan ruang yang didorong perkembangannya dan sesuai dengan rencana tata ruang, sedang disinsentif diberlakukan bagi kawasan yang dibatasi atau dikendalikan perkembangannya bahkan dilarang dikembangkan untuk kegiatan budidaya. Sedangkan instrumen arahan sanksi merupakan acuan dalam pengenaan sanksi kepada pelanggar pemanfaatan ruang, sanksi dikenakan kepada setiap orang yang melakukan pelanggaran penataan ruang. Pelanggaran dalam pemanfaatan ruang diantaranya berupa pemanfaatan ruang yang tidak sesuai dengan rencana tata ruang, tidak sesuai dengan izin pemanfaatan ruang yang diberikan, tidak sesuai dengan persyaratan izin yang diberikan, dan pemanfaatan ruang yang menghalangi akses terhadap kawasan dinyatakan oleh peraturan perundang-undangan sebagai milik umum.

2. Tata Ruang Kawasan Hutan

Dalam Pasal 12 UU Nomor 41 Tahun 1999 tentang Kehutanan, mengatur bahwa kegiatan perencanaan kehutanan meliputi inventarisasi hutan, pengukuhan kawasan hutan, penatagunaan kawasan hutan, pembentukan wilayah pengelolaan hutan, dan penyusunan rencana kehutanan. Secara umum rencana kehutanan terdiri atas rencana kawasan hutan dan rencana pembangunan kehutanan. Berdasarkan skala geografis, rencana kawasan hutan terdiri atas Rencana Kehutanan Tingkat Nasional (RKTN), Rencana Kehutanan Tingkat Provinsi (RKTP), Rencana Kehutanan Tingkat Kabupaten (RKTK) dan Rencana Pengelolaan Hutan di Tingkat Kesatuan Pengelolaan Hutan (RKPH). Rencana kehutanan baik di tingkat nasional (RKTN), tingkat provinsi (RKTP), tingkat kabupaten (RKTK) maupun tingkat pengelolaan hutan (RKPH) merupakan suatu kebutuhan yang sangat mendasar untuk memberikan arah pengurusan hutan ke depan melalui pemanfaatan secara optimal dan lestari, potensi multi fungsi hutan untuk kesejahteraan rakyat serta untuk meningkatkan kontribusi nyata sektor kehutanan bagi kepentingan lingkungan global.

Rencana Kehutanan Tingkat Provinsi (RKTP) yaitu rencana yang berisi arahan-arahan makro pemanfaatan dan penggunaan spasial atau ruang dan potensi kawasan hutan untuk pembangunan kehutanan dan pembangunan di luar kehutanan yang menggunakan kawasan hutan serta perkiraan kontribusi sektor kehutanan di wilayah provinsi untuk jangka waktu 20 tahun. Terkait dengan penyusunan perencanaan kehutanan, Undang-Undang No. 23 Tahun 2014 tentang Pemerintahan Daerah (UU Pemda), tidak memberikan kewenangan perencanaan 
Fungsi Rencana Tata Ruang Wilayah Provinsi Sebagai Instrumen Hukum Pengendalian Pemanfaatan Ruang

kehutanan secara eksplisit bagi provinsi maupun kabupaten/kota. ${ }^{7}$ Urusan perencanaan kehutanan menjadi kewenangan Pemerintah Pusat. Kewenangan Provinsi dalam perencanaan kehutanan hanya sebatas membantu perencanaan kehutanan. Bentuknya dapat berupa usulan pertimbangan teknis perencanaan kehutanan, misalnya usulan perubahan peruntukan dan fungsi kawasan, penetapan Kesatuan Pengelolaan Hutan $(\mathrm{KPH})^{8}$. Sedangkan kewenangan Pemerintah Daerah Provinsi dalam pengelolaan hutan yaitu Pelaksanaan tata hutan pada Kesatuan Pengelolaan Hutan (KPH), kecuali pada KPH Konservasi (KPHK), pemanfaatan hutan di kawasan hutan produksi dan hutan lindung, meliputi: Pemanfaatan kawasan hutan, hasil hutan bukan kayu, Pemungutan hasil hutan, Pemanfaatan jasa lingkungan, kecuali pemanfaatan penyimpanan dan/atau penyerapan karbon, rehabilitasi di luar kawasan hutan Negara, perlindungan hutan di hutan lindung dan hutan produksi, pengolahan hasil hutan bukan kayu, pengolahan hasil hutan kayu dengan kapasitas produksi $<6000 \mathrm{~m} /$ tahun, pengelolaan KHDTK untuk kepentingan religi. ${ }^{9}$

Dari uraian di atas, jelaslah bahwa penataan ruang kawasan hutan menjadi kewenangan pemerintah pusat yaitu Kementerian Lingkungan Hidup dan Kehutanan, posisi pemerintah daerah hanya sebatas membantu dalam bentuk usulan pertimbangan teknis perencanaan kehutanan saja.

3. RTRWP sebagai instrumen hukum pengendalian pemanfaatan ruang kawasan hutan

Kaitan RTRWP dan rencana tata ruang kawasan hutan yaitu berkenaan dengan penetapan rencana pola ruang wilayah provinsi. Rencana pola ruang wilayah provinsi merupakan rencana distribusi peruntukan ruang dalam wilayah provinsi yang meliputi rencana peruntukan ruang untuk fungsi lindung dan rencana peruntukan ruang untuk fungsi budidaya. Alokasi Kawasan Lindung ditujukan bagi pelestarian fungsi lingkungan dalam wilayah provinsi, mengatur keseimbangan dan keserasian peruntukan ruang. Sedangkan alokasi Kawasan Budidaya yaitu untuk pemanfaatan berbagai kegiatan sosial ekonomi.

\footnotetext{
7 Lihat Steni, Bernadinus, 2016, Membedah UU Pemerintahan Daerah yang Baru: Apa yang Baru dalam Pembagian Urusan dan Kewenangan Pusat --Daerah di Bidang Sumber Daya Alam, Ringkasan Eksekutif, Jakarta: INOBU (Institut Penelitian Inovasi Bumi), hlm. ii. Lihat ttps://earthinnovation.org/wp-content/uploads/2014/09/INOBUReport-Membedah-UU-Pemerintahan-Daerah-yang-Baru.pdf., diakses, 9 September 2019.

8 Sistem pengelolaan unit terkecil di tingkat tapak yang diatur dalam ketentuan Pasal 10, 12, dan 17 ayat (1) UU Kehutanan, yang sekarang disebut Kesatuan Pengelolaan Hutan (KPH). Konsep dasar dari KPH yaitu menggeser peran birokrat kehutanan dari peran administratur (Forest Administrator) menjadi peran manajerial (Forest Manager), sehingga diharapkan dapat meningkatkan transparansi dan akuntabilitas tata kelola hutan. Konsep $\mathrm{KPH}$, diharapkan menjadi dasar agar terlaksananya sistem pengelolaan hutan yang lestari dan berkeadilan, lihat Kartodihardjo H, Suwarno E., 2014, Pengarusutamaan Kesatuan Pengelolaan Hutan (KPH) dalam Kebijakan dan Pelaksanaan Perizinan Kehutanan, Direktorat Wilayah Pengelolaan dan Penyiapan Areal Pemanfaatan Kawasan Hutan, Direktorat Jenderal Planologi Kehutanan, Jakarta, hlm. iii.

${ }_{9}$ Lihat Pembagian Urusan Pemerintahan Bidang Kehutanan pada lampiran UU No. 23 Tahun 2014 tentang Pemerintahan Daerah.
} 
Berkaitan dengan penataan ruang kawasan hutan, Pasal 14 UU Kehutanan, menyatakan bahwa Pemerintah menyelenggarakan pengukuhan kawasan hutan. Kegiatan pengukuhan kawasan hutan dilakukan untuk memberikan kepastian hukum atas kawasan hutan. Pada Pasal 15 disebutkan bahwa Pengukuhan kawasan hutan dilakukan melalui proses atau tahapan: penunjukan kawasan hutan, penataan batas kawasan hutan, pemetaan kawasan hutan, dan penetapan kawasan hutan.

Dalam kegiatan pengukuhan kawasan hutan dilakukan dengan memperhatikan rencana tata ruang wilayah. Artinya RTRWP harus mengakomodasi hasil pengukuhan kawasan hutan. Sebaliknya bila terjadi perubahan peruntukan dan atau perubahan fungsi kawasan hutan juga harus diakomodasi dalam RTRWP. Hasil pengukuhan kawasan hutan harus diintegrasikan ke dalam pola ruang RTRWP, yang berarti bahwa rencana pengelolaan ruang kawasan hutan yang telah ditetapkan dengan Surat Keputusan Menteri sesuai dengan peruntukan dan fungsinya, akan menjadi bagian dari RTRWP yang selanjutnya juga akan ditetapkan dengan instrumen hukum berupa peraturan daerah.

Dengan demikian kedudukan RTRWP hanya mengakomodasi tata ruang kawasan hutan yang perencanaannya telah ditetapkan oleh pemerintah pusat. Tidak ada kewenangan pemerintah provinsi untuk mengubah, menambah ataupun mengurangi perencanaan tata ruang kawasan hutan yang telah dikukuhkan/ditetapkan. Oleh karena itu, posisi pemerintah provinsi dalam melaksanakan RTRWP sebagai instrumen hukum dalam pengendalian pemanfaatan ruang kawasan hutan, bukan hanya dalam kapasitas menegakkan Perda RTRWP saja, tetapi juga dalam rangka ikut mengawasi agar ruang kawasan hutan yang telah dikukuhkan/ditetapkan oleh pemerintah pusat, tetap terjaga dan terlindungi sesuai dengan peruntukan dan fungsi dari masing-masing jenis kawasan hutan. Pemerintah provinsi melakukan pengawasan dari aspek zonasi kawasan hutan agar pemanfaatannya sesuai dengan peruntukan dan fungsinya, aspek perizinan pemanfaatan kawasan hutan, pemberian insentif dan disinsentif dalam pengelolaan kawasan hutan, serta penegakan hukum (penerapan sanksi) dalam hal terdapat penyimpangan dalam pemanfaatan kawasan hutan. 
Fungsi Rencana Tata Ruang Wilayah Provinsi Sebagai Instrumen Hukum Pengendalian Pemanfaatan Ruang

\section{Faktor Penyebab Malfungsi RTRWP Sebagai Instrumen Hukum Pengendalian Pemanfaatan Ruang Kawasan Hutan}

da 2 (dua) faktor utama yang menyebabkan terjadinya malfungsi RTRWP sebagai
instrumen hukum pengendalian pemanfaatan ruang kawasan hutan, yaitu faktor substansi ruang kawasan hutan dalam RTRWP dan faktor implementasi RTRWP.

1. Substansi RTRWP

a. Luas kawasan hutan

Berkenaan dengan penetapan substansi sektor kehutanan dalam RTRWP, terdapat ketidaksesuaian luasan kawasan hutan yang ditetapkan dalam RTRWP dengan kawasan hutan yang telah ditetapkan berdasarkan SK penetapannya. Sebagai contoh misalnya yang terjadi di Provinsi Bengkulu sebagaimana data (cetak tebal) pada tabel berikut: ${ }^{10}$

Tabel 1. Posisi Hutan Lindung (HL) dalam RTRW dan SK penunjukan/penetapan

\begin{tabular}{llrrr}
\hline \multirow{2}{*}{ No } & Nama Hutan Lindung & \multicolumn{2}{c}{ Luas (Ha) } & \multirow{2}{*}{ Keterangan } \\
\cline { 3 - 4 } & & RTRW & \multicolumn{1}{c}{ SK Menhut } & \\
\hline 1 & HL Raja Mandara & 63.284 & $\left.63.284^{*}\right)$ & \\
\hline 2 & HL Bukit Sanggul & $\mathbf{7 0 . 9 2 4}$ & $\mathbf{7 4 . 1 5 2 , 5 1}$ & \\
\hline 3 & HL Bukit Riki & 4.370 & \multicolumn{1}{c}{$\left.4.370^{*}\right)$} & \\
\hline 4 & HL Bukit Daun & $\mathbf{9 0 . 8 0 0}$ & $\mathbf{8 3 . 4 3 7 , 1 1}$ & \\
\hline 5 & HL Kokobuwabuwa & 3.450 & $\left.3.450^{*}\right)$ & \\
\hline 6 & HL Rimbo Donok & $\mathbf{4 3 3}$ & $\mathbf{3 7 7 , 9 9 ^ { * } )}$ & \\
\hline 7 & HL Balai Rejang & 18.069 & $\left.18.069^{*}\right)$ & Jadi HPT \\
\hline 8 & HL Bukit Basa & $\mathbf{1 2 8}$ & $\mathbf{1 2 5 , 3 6}$ & \\
\hline 9 & HL Konak & 11 & $\left.11,11^{*}\right)$ & \\
\hline 10 & HL Rimbo Pengadang & - & $2.487,51$ & \\
\hline 11 & HL Semidang Bukit Kabu & - & 397,83 & \\
\hline
\end{tabular}

Sumber: Dokumen RTRWP Bengkulu, 2012 dan SK Menhut 784 Tahun 2012 dan atau SK Penetapan kawasan hutan.

*): statusnya telah penetapan kawasan.

10 Dinas Lingkungan Hidup dan Kehutanan Provinsi Bengkulu, 2017, “Review Rencana Tata Ruang Wilayah (RTRWP) Bidang Kehutanan", Laporan, Desember, hlm. 23-30. 
Tabel 2. Posisi Kawasan Suaka Alam (KSA), Kawasan Pelestarian Alam (KPA), dan Taman Buru (TB) dalam RTRW dan SK penunjukan/penetapan

\begin{tabular}{|c|c|c|c|c|}
\hline \multirow[t]{2}{*}{ No } & \multirow[t]{2}{*}{ Nama Kawasan Hutan } & \multicolumn{2}{|c|}{ Luas (Ha) } & \multirow[t]{2}{*}{ Keterangan } \\
\hline & & RTRW & SK Menhut & \\
\hline 1 & Cagar Alam (CA) Mukomuko 1 & 230 & $\left.432,72^{*}\right)$ & \\
\hline 2 & CA Mukomuko 2 & 103 & $\left.103,50^{*}\right)$ & \\
\hline 3 & CA Air Rami 1 & 233 & $\left.306,15^{*}\right)$ & Digabung dalam 1 \\
\hline 4 & CA Air Rami 2 & 38 & & SK \\
\hline 5 & CA Danau Menghijau & 139 & $\left.154,10^{*}\right)$ & \\
\hline 6 & CA Danau Tes & 2.882 & $\left.2.724,46^{*}\right)$ & \\
\hline 7 & CA Talang Ulu 1 dan 2 & $@<1$ & $\left.0,56^{*}\right)$ & \\
\hline 8 & CA Pagar Gunung 1, 2, 3, 4, 5 & $@<1$ & $\left.2,6^{*}\right)$ & \\
\hline 9 & CA Seblat & 89 & $\left.99,44^{*}\right)$ & \\
\hline 10 & CA Danau Dusun Besar & 577 & $\left.577^{*}\right)$ & \\
\hline 11 & CA Taba Penanjung 1 dan 2 & @ 2 & $\left.3,7^{*}\right)$ & \\
\hline 12 & CA Tanjung Laksaha & 333 & $\left.360,53^{*}\right)$ & \\
\hline 13 & CA Teluk Klowe & 331 & $\left.1.344,29^{*}\right)$ & Digabung dalam 1 \\
\hline 14 & CA Sungai Bahewo & 495 & & SK \\
\hline 15 & CA Kloyo 1,2 & 305 & $\left.305^{*}\right)$ & \\
\hline 16 & CA Pasar Seluma & 159 & $\left.159^{*}\right)$ & \\
\hline 17 & CA Pasar Ngalam & 256 & $\left.69,50^{*}\right)$ & \\
\hline 18 & CA Pasar Talo & 487 & $\left.487^{*}\right)$ & \\
\hline 19 & CA Air Alas & 59 & $\left.59,50^{*}\right)$ & \\
\hline 20 & Taman Wisata Alam (TWA) Air Hitam & 433 & $\left.433^{*}\right)$ & \\
\hline 21 & TWA Bukit Kaba & 13.490 & $\left.14.650,51^{*}\right)$ & \\
\hline \multirow[t]{2}{*}{22} & TWA Pantai Panjang-Pulau & 967,20 & $1.172,64$ & Belum penetapan \\
\hline & Baai & & & \\
\hline \multirow[t]{2}{*}{23} & TWA Lubuk Tapi-Kayu & 6 & $\left.11,72^{*}\right)$ & \\
\hline & Ajaran & & & \\
\hline 24 & TWA Way Hawang & 64 & $\left.64^{*}\right)$ & \\
\hline 25 & TWA Seblat & - & $\left.7.732,8^{*}\right)$ & Tidak ada di RTRW \\
\hline 26 & TWA Lebong Kandis & - & 862 & Tidak ada di RTRW \\
\hline 27 & TN Kerinci Seblat & 340.577 & $\left.340.577^{*}\right)$ & \\
\hline 28 & TN Bukit Barisan Selatan & 64.711 & $\left.64.711^{*}\right)$ & \\
\hline 29 & Tahura Raja Lelo & 1.122 & $\left.1.122^{*}\right)$ & \\
\hline 30 & Tahura Gluguran & 586 & 586,01 & \\
\hline 31 & TB Semidang Bukit Kabu & 9.031 & $9.207,53$ & Belum penetapan \\
\hline 32 & TB Gunung Nanua & 7.271 & $\left.7.271^{*}\right)$ & \\
\hline
\end{tabular}


Fungsi Rencana Tata Ruang Wilayah Provinsi Sebagai Instrumen Hukum Pengendalian Pemanfaatan Ruang

Sumber: Dokumen RTRWP Bengkulu, 2012 dan SK Menhut 784 tahun 2012 dan atau SK

Penetapan kawasan hutan

*): statusnya telah penetapan kawasan

Tabel 3. Posisi Hutan Produksi Terbatas (HPT), Hutan Produksi Tetap (HP) dan Hutan

Produksi yang dapat dikonversi (HPK) dalam RTRW dan SK penunjukan/penetapan

\begin{tabular}{|c|c|c|c|c|}
\hline \multirow[t]{2}{*}{ No } & \multirow[t]{2}{*}{ Nama Kawasan Hutan } & \multicolumn{2}{|c|}{ Luas (Ha) } & \multirow[t]{2}{*}{ Keterangan } \\
\hline & & RTRW & SK Menhut & \\
\hline 1 & HPT Air Majunto & 28.763 & $\left.28.763,42^{*}\right)$ & \\
\hline 2 & HPT Air Ipuh 1 & 20.544 & $19.659,94$ & \\
\hline 3 & HPT Air Ipuh 2 & 20.667 & $16.734,92$ & \\
\hline 4 & HPT Lebong Kandis & 31.967 & $\left.28.493,89^{*}\right)$ & \\
\hline 5 & HPT Air Ketahun & 15.011 & $14.447,27$ & \\
\hline 6 & HPT Hulu Malakoni & 2.191 & $\left.2.388,49^{*}\right)$ & \\
\hline 7 & HPT Bukit Badas & 9.044 & $\left.9.044,42^{*}\right)$ & \\
\hline 8 & HPT Bukit Rabang & 6.849 & $\left.6.848,54^{*}\right)$ & \\
\hline 9 & HPT Peraduan Tinggi & 9.158 & $\left.9.158,42^{*}\right)$ & \\
\hline 10 & HPT Air Kedurang & 5.247 & $\left.5.247,32^{*}\right)$ & \\
\hline 11 & HPT Air Kinal & 5.568 & $\left.5.567,77^{*}\right)$ & \\
\hline 12 & HPT Kaur Tengah & 13.932 & $\left.13.932,27^{*}\right)$ & \\
\hline 13 & HPT Bukit Kumbang & 10.733 & $\left.10,732,91^{*}\right)$ & \\
\hline 14 & HPT Bukit Basa & & 125 & Tidak ada di RTRW \\
\hline 15 & HPT Bukit Sanggul & & 2.305 & Tidak ada di RTRW \\
\hline 16 & HPT Air Talo & & $\left.2.533,79^{*}\right)$ & Tidak ada di RTRW \\
\hline 17 & HPT Rindu Hati & & 2,827 & Tidak ada di RTRW \\
\hline 18 & HPT Urai Serangai & & 2.060 & Tidak ada di RTRW \\
\hline 19 & HP Air Dikit & 2.730 & $\left.2.260,42^{*}\right)$ & \\
\hline 20 & HP Air Teramang & 4.854 & $\left.4.780,60^{*}\right)$ & \\
\hline 21 & HP Air Rami & 13.763 & $\left.14.263^{*}\right)$ & \\
\hline 22 & HP Urai Serangai & 6.640 & & Jadi HPT dan HPK \\
\hline 23 & HP Air Bintunan & 3.461 & & Jadi HPK \\
\hline 24 & HP Rindu Hati 1 dan 2 & 1.046 & 357,23 & \\
\hline 25 & HP Air Bengkenang & 1.579 & $\left.1.701,86^{*}\right)$ & \\
\hline 26 & HP Air Sambat & 1.938 & $2.096,40$ & \\
\hline 27 & HP Semidang Bukit Kabu & - & 660 & Tidak ada di RTRW \\
\hline 28 & HPK Air Seblat & - & 2.927 & Tidak ada di RTRW \\
\hline 29 & HPK Air Urai-Serangai & - & 2.060 & Tidak ada di RTRW \\
\hline 30 & HPK Air Bintunan & - & 2.927 & Tidak ada di RTRW \\
\hline
\end{tabular}




\begin{tabular}{lllrl}
\hline 31 & HPK Air Majunto 1 & - & $\mathbf{8 4 7}$ & Tidak ada di RTRW \\
\hline 32 & HPK Air Majunto 2 & - & $\mathbf{2 . 0 3 8}$ & Tidak ada di RTRW \\
\hline
\end{tabular}

Sumber: Dokumen RTRWP Bengkulu, 2012 dan SK Menhut 784 Tahun 2012 dan atau SK Penetapan kawasan hutan

*): statusnya telah penetapan kawasan

Selain ruang kawasan hutan yang telah dikukuhkan/ditetapkan berdasarkan SK Menteri yang penetapan luasnya tidak sama dengan yang ditetapkan dalam RTRW, ada juga ruang kawasan hutan yang telah ditetapkan, namun tidak terakomodasi dalam RTRWP, seperti halnya TWA Seblat dan TWA Lebong Kandis, dan beberapa HPT, HP, dan HPK. Kondisi demikian ini tentunya dapat menimbulkan ketidakpastian hukum, dan akan menimbulkan persoalan dalam pelaksanaannya di lapangan, sehingga langkah-langkah kebijakan yang dilakukan oleh pengambil keputusan menjadi tidak jelas dan tidak terukur.

Akibatnya sudah patut diduga bahwa fungsi RTRWP sebagai sebuah instrumen hukum untuk mengendalikan pemanfaatan ruang kawasan hutan dalam rangka menjaga kelestarian dan keberlanjutan fungsi kawasan hutan tidak akan berjalan dengan baik. Ketidaksesuaian antara kawasan hutan yang ditetapkan oleh Menteri dengan yang tercantum dalam RTRWP yang demikian ini, tidak tertutup kemungkinan juga terjadi di wilayah provinsi lainnya, luasan kawasan yang telah ditetapkan oleh Menteri tidak terakomodasi dengan baik dalam RTRWP.11 b. Peta dan tata batas ruang kawasan hutan tidak akurat

Titik persoalan pada tahap penataan batas ruang kawasan hutan terletak pada ketidaksamaan pemaknaan (tidak akurat) dalam proses pemetaan dan pada proses tata batas. Ketidakakuratan peta penunjukan kawasan hutan mengakibatkan proses pengukuhan kawasan hutan ${ }^{12}$ lebih lanjut sulit dituntaskan, termasuk proses inventarisasi hak-hak masyarakat pada saat penataan batas. Pemetaan kawasan hutan adalah kegiatan pemetaan hasil pengukuhan kawasan hutan sesuai dengan tahapannya. Penetapan kawasan hutan yaitu penetapan kawasan hutan temu gelang yang memuat letak, batas, luas, fungsi tertentu dan titik-titik koordinat batas kawasan hutan yang dituangkan dalam bentuk peta kawasan hutan skala tertentu atau minimal skala 1:100.000. Pada kenyataannya, sampai saat ini dalam proses

\footnotetext{
${ }^{11}$ Lihat Eko N Setiawan, dkk., 2017, “Konflik Tata Ruang Kehutanan Dengan Tata Ruang Wilayah (Studi Kasus Penggunaan Kawasan Hutan Tidak Prosedural untuk Perkebunan Sawit Provinsi Kalimantan Tengah)", Jurnal Bhumi Vol. 3 No. 1 Mei, hlm. 64.

12 Pengukuhan kawasan hutan adalah rangkaian kegiatan penunjukan, penataan batas, dan penetapan kawasan hutan, lihat Pasal 1 angka 3 Peraturan Menteri Kehutanan Nomor : P.62/Menhut-II/2013 Tentang Perubahan Atas Peraturan Menteri Kehutanan Nomor P.44/Menhut-II/ 2012 tentang Pengukuhan Kawasan Hutan.
} 
Fungsi Rencana Tata Ruang Wilayah Provinsi Sebagai Instrumen Hukum Pengendalian Pemanfaatan Ruang

penetapan kawasan hutan hanya sampai tata batas tapi tidak temu gelang. Selain itu, Penerbitan peta kawasan hutan dengan skala 1:100.000 belum mampu memberikan kepastian hukum atas batas dan letak dari status dan fungsi hutan. Hal ini dapat berdampak pada ketidakpastian batas di lapangan ketika harus dirujuk dengan peta. ${ }^{13}$

Penataan batas ruang kawasan hutan, seharusnya merupakan proses menyelesaikan permasalahan konflik sektor kehutanan, misalnya terdapat hak masyarakat yang kemungkinan masuk ke dalam kawasan hutan atau sebaliknya masyarakat tanpa legalitas memanfaatkan kawasan hutan, jadi kegiatan penataan batas ruang kawasan hutan bukan sekadar memasang patok. Oleh karena itu, jika pemetaan dan penetapan tata batas ruang kawasan hutan tidak dilakukan dengan objektif dan tertib, maka persoalan konflik dan tumpang tindih dalam pemanfaatan ruang kawasan hutan tidak akan pernah dapat diselesaikan. Bahkan terhadap kawasan hutan yang sudah ditetapkan statusnya, masih ada hak pihak lain yang akan menguasainya. Hal ini menunjukkan bahwa proses pengukuhan kawasan hutan (penunjukan, pemetaan, tata batas dan penetapan), belum berjalan dengan baik. ${ }^{14}$ Kondisi demikian ini menjadi faktor substansial terjadinya malfungsi RTRWP, karena peta dan tata batas ruang kawasan hutan tidak akurat.

c. Kondisi eksisting kawasan hutan

Kondisi eksisting luasan kawasan hutan pada saat pengukuhan, baik pada saat penunjukan, pemetaan, tata batas dan penetapannya, pada kenyataannya seringkali tidak sesuai dengan realitas yang ada di lapangan. Kondisi eksisting kawasan yang ditetapkan misalnya untuk fungsi lindung atau fungsi konservasi dalam RTRWP ternyata sebagian sudah tidak berhutan lagi, dan ini berarti kawasan hutan yang tersisa sebenarnya lebih sedikit dari yang sudah dialokasikan sebagai Kawasan Lindung atau Kawasan Konservasi. Berkurangnya kawasan hutan ini dapat terjadi akibat ada perubahan status Kawasan Lindung menjadi Kawasan Budidaya. ${ }^{15}$ Kawasan Lindung yang statusnya berubah tersebut lazimnya terjadi hampir di setiap daerah. Sementara di sisi lain juga terjadi perubahan status dari yang sebelumnya sebagai Kawasan Budidaya menjadi Kawasan Lindung. Meskipun ada

\footnotetext{
${ }^{13}$ Lihat Pernando Sinabutar, et.al., 2015, “Kepastian Hukum Dan Pengakuan Para Pihak Hasil Pengukuhan Kawasan Hutan Negara di Provinsi Riau (Legal Certainty and Legitimacy of State Forest Gazettment in Riau Province, Indonesia)", Jurnal Analisis Kebijakan Kehutanan, Vol. 12 No. 1, April, hlm. 30.

${ }^{14}$ Lihat Desmiwati dan Surati, 2017, “Upaya Penyelesaian Masalah Pemantapan Kawasan Hutan Pada Taman Nasional Di Pulau Sumatra (Efforts To Resolve The Problem Of Forest Area Conservation On The National Park In The Island Of Sumatra)", Jurnal Penelitian Kehutanan Wallacea, Vol. 6 No.2, Agustus, hlm. 144.

${ }^{15}$ Lihat Iskandar, 2011, “Aktualisasi Prinsip Hukum Pelestarian Fungsi Lingkungan Hidup Dalam Kebijakan Perubahan Peruntukan, Fungsi, dan Penggunaan Kawasan Hutan”, Jurnal Dinamika Hukum, Vol. 11 No. 3 , September, hlm. 513 .
} 
penambahan untuk Kawasan Lindung namun perbandingan antara luas yang hilang dan bertambah tetap tidak seimbang. Hal ini terjadi karena inkonsistensi kebijakan pemanfaatan ruang kawasan hutan yang telah ditetapkan berdasarkan SK Menteri dan dicantumkan dalam Perda RTRWP.

d. Aspek daya dukung lingkungan

Faktor lain yang berkenaan dengan substansi tata ruang kawasan hutan dalam RTRWP yaitu bahwa RTRWP disusun dengan tidak memperhitungkan atau tanpa dikaji aspek strategis terkait dengan keserasian, keselarasan, keseimbangan, kelestarian lingkungan, dan keberlanjutan dalam pemanfaatan fungsi kawasan hutan. Sehingga aspek daya dukung lingkungan dalam penyusunan RTRWP menjadi terabaikan. Akibatnya RTRWP tidak dapat berfungsi sebagai instrumen untuk mencegah laju kerusakan ruang kawasan hutan. Oleh karena itu, jika RTRWP tersebut dijalankan maka diperkirakan akan berakibat fatal bagi keberadaan ruang kawasan hutan dan keberlanjutan fungsi lingkungan hidup.

\section{Implementasi RTRWP}

a. Tumpang tindih kebijakan dalam pemanfaatan ruang kawasan hutan

Tumpang tindih dalam pemanfaatan kawasan hutan menjadi salah satu faktor penyebab malfungsi RTRWP. Permasalahan tumpang tindih penggunaan dan pemanfaatan lahan yang berdampak pada eksistensi kawasan hutan, diantaranya yaitu adanya Izin Lokasi yang diterbitkan oleh pemerintah daerah (Bupati) yang tumpang tindih dengan peruntukan atau perizinan lainnya di kawasan hutan, usaha pada sektor perkebunan yang sudah operasional (merambah) sebelum diterbitkannya SK pelepasan kawasan hutan oleh Menteri, ${ }^{16}$ adanya izin konsesi kegiatan pertambangan di dalam kawasan hutan konservasi dan hutan lindung atau berada pada lokasi yang semula peruntukannya untuk lokasi perkebunan, penguasaan lahan oleh masyarakat (perambahan) untuk kepentingan pemukiman, ladang, sawah, kebun di dalam kawasan hutan. ${ }^{17}$ Dengan kondisi yang demikian, ditetapkannya tata ruang kawasan hutan dalam RTRWP menjadi tidak bermakna, karena fungsi mengatur dan menata dari Perda RTRWP tidak berjalan sebagaimana mestinya.

\footnotetext{
${ }^{16}$ Lihat Iskandar, 2015, Hukum Kehutanan, Prinsip Hukum Pelestarian Fungsi Lingkungan Hidup dalam Kebijakan Pengelolaan Kawasan Hutan Berkelanjutan, Bandung: Mandar Maju, hlm. 15.

17Iskandar, 2013, “Tinjauan Yuridis Tukar Menukar dan pelepasan Kawasan Hutan Untuk Kepentingan Nonkehutanan", Majalah Ilmu Hukum Kertha Wicaksana, FH, Universitas Warmadewa Denpasar, Bali, Volume 19 No. 1, Januari, hlm. 65-67.
} 
b. Inkonsistensi dalam pengendalian ruang kawasan hutan

Komitmen dan konsisten dalam mengimplementasikan RTRWP merupakan sikap yang harus dimiliki oleh pemerintah daerah untuk dapat mewujudkan pelestarian dan keberlanjutan fungsi kawasan hutan. Namun, fakta yang terjadi dalam pemanfaatan ruang kawasan hutan terjadi tarik-menarik pemanfaatan untuk kepentingan non kehutanan (bisnis) dengan dalih investasi di daerah, yang pada akhirnya berdampak pada inkonsistensi dalam pemanfaatan ruang kawasan hutan. Inkonsistensi ini terlihat dari usulan revisi tata ruang wilayah di berbagai daerah, dengan alasan perkembangan dinamika pembangunan daerah dan rasionalisasi RTRWP. Sebagai contoh, dengan dalih status hutan lindung tidak berhutan atau sudah bermukimnya masyarakat, pemerintah daerah mengusulkan revisi tata ruang ke pemerintah pusat agar melepaskan kawasan hutan menjadi hutan produksi atau areal penggunaan lain.

c. Konflik pemanfaatan ruang kawasan hutan

Konflik kepentingan antar lembaga dalam pemanfaatan ruang kawasan hutan juga tidak jarang terjadi, misalnya terkait dengan tumpang tindih perizinan sektoral, konflik dalam perizinan penggunaan kawasan hutan tanpa melalui prosedur pelepasan kawasan hutan. Kebijakan pemekaran desa juga turut andil menciptakan konflik pemanfaatan ruang kawasan hutan, terutama pemekaran desa yang wilayahnya berbatasan dengan kawasan hutan, konflik yang terjadi antara masyarakat lokal dengan pemegang Izin Pemanfaatan Ruang kawasan hutan, kebijakan perubahan peruntukan kawasan hutan tidak diikuti dengan peningkatan kegiatan ekonomi daerah dan kesejahteraan masyarakat, juga dapat menjadi sumber konflik. Kondisi demikian tentunya menjadi sangat ironis, karena filosofi dari penetapan RTRWP yaitu agar tercipta ketertiban dan keteraturan serta kesejahteraan bagi rakyat daerah.

d. Lemahnya penegakan hukum atas pelanggaran pemanfaatan ruang kawasan hutan

Lemahnya penegakan hukum perda RTRWP juga menjadi salah satu faktor terjadinya malfungsi RTRWP. Fakta di lapangan terjadi pembiaran terhadap pelanggaran ketentuan Perda RTRWP. Artinya bahwa setiap orang yang melakukan penyimpangan pemanfaatan ruang kawasan hutan tidak diberikan sanksi yang tegas. Padahal penegakan hukum atas pelanggaran tata ruang kawasan hutan sebagaimana diatur dalam Perda RTRWP, dapat dikenakan sanksi tidak hanya berdasarkan Perda RTRWP tapi juga atas dasar ketentuan peraturan sektoral lainnya. Penegakan hukum tata ruang dalam hal ini tidak hanya bersifat 
represif, tetapi juga bersifat preventif, ${ }^{18}$ dengan adanya penegakan hukum, maka hukum itu menjadi nyata.

Namun demikian, apabila telah terjadi pelanggaran, maka terhadap setiap pelaku pelanggaran dalam pemanfaatan ruang kawasan hutan, seharusnya dikenakan sanksi secara tegas sesuai dengan ketentuan yang berlaku. Bukan hanya sanksi yang bersifat administratif dan keperdataan, tapi juga sanksi pidana, jika memang pelanggaran tersebut telah memenuhi unsur-unsur delik pidana. Bahkan apabila pejabat pemerintah yang berwenang menerbitkan izin tidak sesuai dengan RTRWP dapat dikenakan sanksi pidana. Penerapan sanksi hukum pidana sangat diperlukan apalagi kalau pelanggaran hukum tersebut telah menimbulkan dampak kerusakan terhadap ekosistem kawasan hutan dan lingkungan hidup. ${ }^{19}$

\section{Solusi Agar RTRWP Dapat Berfungsi Secara Optimal Sebagai Instrumen Hukum Pengendalian Pemanfaatan Ruang Kawasan Hutan}

$\mathrm{F}$ akta yang terjadi sebagaimana uraian di atas, RTRWP yang di dalamnya juga telah ditetapkan tata ruang kawasan hutan sebagai bagian dari pola ruang RTRWP belum dapat berfungsi sesuai dengan maksud ditetapkannya RTRWP. Persoalan ini tentunya harus dicarikan solusinya, agar ruang kawasan hutan yang masih ada dalam pemanfaatannya tetap sesuai dengan peruntukan dan fungsinya. Apabila terjadi pembiaran tanpa solusi, maka dapat dipastikan luasan kawasan hutan yang ada saat ini akan semakin menyusut dan tentunya akan sangat mempengaruhi daya dukung lingkungan terhadap proses ekologis.

Beberapa langkah kebijakan strategis yang dapat dilakukan baik oleh Pemerintah maupun pemerintah daerah agar tidak terjadi malfungsi RTRWP sebagai instrumen hukum pengendalian dalam pemanfaatan ruang kawasan hutan, terutama apabila akan dilakukan revisi/perubahan RTRWP yaitu:

\section{Substansi RTRWP}

Untuk mengatasi permasalahan substansi ruang kawasan hutan dalam RTRWP, terkait dengan data luasan kawasan hutan, peta dan tata batas kawasan hutan, kondisi eksisting kawasan hutan di lapangan, maka perlu dilakukan analisis daya dukung lingkungan, guna mengkaji aspek sosial, ekonomi, dan lingkungan, serta pertimbangan teknis lainnya. Kepastian hukum terkait dengan status, peruntukan dan fungsi, serta tata batas kawasan hutan akan

\footnotetext{
${ }^{18}$ Lihat Sundari Rangkuti, 2000, Hukum Lingkungan dan Kebijaksanaan Lingkungan Nasional (Edisi Kedua), Surabaya: Airlangga University Press, hlm. 209-210.

${ }^{19}$ Dalam Perda RTRWP lazimnya mengatur sanksi, baik sanksi administrasi, perdata dan juga pidana, demikian juga dalam undang-undang sektoral.
} 
Fungsi Rencana Tata Ruang Wilayah Provinsi Sebagai Instrumen Hukum Pengendalian Pemanfaatan Ruang

memudahkan pelaksanaan pengendalian pemanfaatan ruang kawasan hutan. Terkait dengan hal ini upaya yang dapat dilakukan diantaranya yaitu dengan mempercepat terwujudnya kepastian status hukum kawasan hutan melalui inventarisasi kondisi eksisting kawasan hutan, penyelesaian tata batas kawasan dan tata batas peruntukan dan fungsi kawasan hutan dengan melibatkan semua pihak/stakeholders yang terkait, termasuk masyarakat yang berada di sekitar kawasan hutan, percepatan penyelesaian pemetaan (peta tematik kawasan hutan) dan pengukuhan/penetapan seluruh kawasan hutan, meningkatkan keterbukaan data dan informasi sumber daya kawasan hutan yang valid, agar semua pihak dapat ikut serta melakukan pengawasan.

2. Implementasi RTRWP

Ada beberapa solusi sebagai langkah kebijakan teknis yang dapat dilakukan yaitu:

a. Agar tumpang tindih kebijakan dalam pemanfaatan ruang kawasan hutan dapat dihindari yaitu dengan mendorong optimalisasi penggunaan kawasan hutan yang sudah dilepaskan untuk kepentingan di luar sektor kehutanan yang ditelantarkan; Dalam penerbitan izin harus dilakukan koordinasi antara pemerintah daerah dengan pemerintah pusat; Penggunaan kawasan hutan untuk kepentingan pembangunan di luar kehutanan hanya dapat dilakukan di dalam kawasan hutan produksi dan hutan lindung, dengan tanpa mengubah fungsi pokok kawasan hutan. Terkait kegiatan pertambangan, penggunaan kawasan hutan harus dilakukan dengan mempertimbangkan batasan luas dan jangka waktu serta kelestarian lingkungan, dan dilarang melakukan penambangan terbuka di kawasan hutan lindung. Penyelesaian tumpang tindih penggunaan ruang kawasan hutan harus dilakukan sesuai dengan ketentuan peraturan perundangundangan, didukung instrumen peta tematik kawasan hutan yang memiliki akurasi tinggi, dan peta ini sekaligus sebagai instrumen dalam melakukan penindakan hukum atas pelanggaran yang terjadi.

b. Untuk mengatasi persoalan inkonsistensi dalam pengendalian pemanfaatan ruang kawasan hutan, maka Pemerintah dan pemerintah daerah harus mengendalikan kebijakan internalnya sendiri melalui pengawasan internal secara berjenjang. Sedangkan secara eksternal yaitu dilakukan pengawasan oleh masyarakat dan atau lembaga swadaya masyarakat (LSM) atau lembaga independen lainnya. Selain itu, instrumen lain yang dapat digunakan untuk meminimalisir inkonsistensi yang terjadi yaitu dengan memantau pemanfaatan ruang kawasan hutan melalui pemanfaatan teknologi citra 
satelit, sehingga dapat dilakukan tindakan pengendalian dan pencegahan lebih lanjut oleh pihak yang berwenang.

c. Untuk mengatasi persoalan konflik dalam pemanfaatan ruang kawasan hutan, perlu dibangun dan dikembangkan berbagai pola kemitraan dengan masyarakat di sekitar kawasan hutan, karena konflik tersebut terjadi lazimnya karena adanya ketimpangan sosial, kemiskinan, dan ketidakadilan.

d. Berkenaan dengan lemahnya penegakan hukum atas pelanggaran pemanfaatan ruang kawasan hutan, upaya yang harus dilakukan diantaranya yaitu meningkatkan kapasitas dan integritas aparatur penegak hukum, baik aparat penegak hukum administrasi (aparat birokrasi) maupun aparat penegak hukum pidana; Meningkatkan pemahaman yang benar tentang hukum kehutanan dan hukum lingkungan melalui berbagai pendidikan dan pelatihan; Meningkatkan koordinasi dalam pengawasan dan penegakan hukum (penerapan sanksi) terhadap penyimpangan pemanfaatan ruang kawasan hutan. Pembentukan Lembaga Pencegahan dan Pemberantasan Perusakan Hutan (P3H), sesuai ketentuan Pasal 54 UU No. 18 Tahun 2013 tentang Pencegahan dan Pemberantasan Perusakan Hutan. Penerapan sanksi merupakan salah satu upaya pengendalian pemanfaatan ruang. Pengenaan sanksi dimaksudkan sebagai perangkat tindakan penertiban atas pemanfaatan ruang yang tidak sesuai dengan rencana tata ruang dan peraturan zonasi. Pengenaan sanksi tidak hanya diberikan kepada pemanfaatan ruang yang tidak sesuai dengan ketentuan perizinan pemanfaatan ruang, tetapi dikenakan pula kepada pejabat pemerintah yang berwenang menerbitkan Izin Pemanfaatan Ruang yang tidak sesuai dengan RTRWP, hal ini sebagaimana diatur dalam ketentuan Pasal 73 ayat (1).

\section{PENUTUP}

Gungsi RTRWP sebagai instrumen hukum dalam pengendalian pemanfaatan ruang 1 kawasan hutan, yaitu agar kawasan hutan tetap terjaga dan terlindungi sesuai dengan peruntukan dan fungsi kawasan hutan. Pemerintah provinsi melalui RTRWP melakukan pengawasan dari aspek zonasi kawasan hutan, aspek perizinan yang menjadi kewenangannya, pemberian insentif dan disinsentif dalam pengelolaan kawasan hutan, serta penegakan hukum (penerapan sanksi) dalam hal terdapat penyimpangan pemanfaatan ruang kawasan hutan. 
Fungsi Rencana Tata Ruang Wilayah Provinsi Sebagai Instrumen Hukum Pengendalian Pemanfaatan Ruang

Faktor yang menyebabkan terjadinya malfungsi RTRWP sebagai instrumen hukum pengendalian pemanfaatan ruang kawasan hutan, yaitu faktor Substansi ruang kawasan hutan dalam RTRWP dan faktor implementasi RTRWP.

Solusi atau upaya untuk mengatasi malfungsi substansi RTRWP terkait dengan substansi diantaranya yaitu: meningkatkan keterbukaan data dan informasi sumber daya kawasan hutan yang valid; percepatan penyelesaian dan penyelesaian tata batas kawasan dan tata batas peruntukan dan fungsi kawasan hutan; mempercepat terwujudnya kepastian status hukum kawasan hutan; sedangkan solusi untuk masalah implementasi yaitu: perlu dukungan instrumen peta tematik kawasan hutan yang memiliki akurasi tinggi; memantau pemanfaatan ruang kawasan hutan melalui pemanfaatan teknologi citra satelit; perlu dibangun dan dikembangkan berbagai pola kemitraan; meningkatkan kapasitas dan integritas aparatur penegak hukum; dan pembentukan Lembaga Pencegahan dan Pemberantasan Perusakan Hutan $(\mathrm{P} 3 \mathrm{H})$ untuk mendukung penegakan hukum.

\section{DAFTAR PUSTAKA}

\section{Buku}

Iskandar, et.al., 2011, Kebijakan Perubahan Kawasan Hutan, Dalam Pengelolaan Berkelanjutan, Unpad Press, Bandung;

Iskandar, 2015, Hukum Kehutanan, Prinsip Hukum Pelestarian Fungsi Lingkungan Hidup Dalam Kebijakan Pengelolaan Kawasan Hutan Berkelanjutan, Mandar Maju, Bandung;

Kartodihardjo H, Suwarno E., 2014, Pengarusutamaan Kesatuan Pengelolaan Hutan (KPH) dalam Kebijakan dan Pelaksanaan Perizinan Kehutanan, Direktorat Wilayah Pengelolaan dan Penyiapan Areal Pemanfaatan Kawasan Hutan, Direktorat Jenderal Planologi Kehutanan, Jakarta;

Sundari Rangkuti, 2000, Hukum Lingkungan dan Kebijaksanaan Lingkungan Nasional (Edisi Kedua), Airlangga University Press, Surabaya.

\section{Jurnal}

Desmiwati dan Surati, 2017, “Upaya Penyelesaian Masalah Pemantapan Kawasan Hutan Pada Taman Nasional Di Pulau Sumatra (Efforts To Resolve The Problem Of Forest Area Conservation On The National Park In The Island Of Sumatra)", Jurnal Penelitian Kehutanan Wallacea, Vol. 6 No.2, Agustus; 
Eko N Setiawan, dkk., 2017, “Konflik Tata Ruang Kehutanan Dengan Tata Ruang Wilayah (Studi Kasus Penggunaan Kawasan Hutan Tidak Prosedural untuk Perkebunan Sawit Provinsi Kalimantan Tengah)", Jurnal Bhumi Vol. 3 No. 1 Mei;

Epi Syahadat, Subarudi, 2012, “Permasalahan Penataan Ruang Kawasan Hutan Dalam Rangka

Revisi Rencana Tata Ruang Wilayah Provinsi (Problems On Forest And Land Use System

For Revision Of Provincial Land Use System)", Jurnal Analisis Kebijakan Kehutanan, Vol. 9

No. 2, Agustus;

Iskandar, 2011, “Aktualisasi Prinsip Hukum Pelestarian Fungsi Lingkungan Hidup Dalam Kebijakan Perubahan Peruntukan, Fungsi, dan Penggunaan Kawasan Hutan", Jurnal Dinamika Hukum, Vol. 11 No. 3, September;

2013, “Tinjauan Yuridis Tukar Menukar dan pelepasan Kawasan Hutan Untuk

Kepentingan Nonkehutanan", Majalah Ilmu Hukum Kertha Wicaksana, FH, Universitas Warmadewa Denpasar, Bali, Vol. 19 No. 1, Januari;

Sinabutar, Pernando, et.al., 2015, “Kepastian Hukum Dan Pengakuan Para Pihak Hasil Pengukuhan Kawasan Hutan Negara Di Provinsi Riau (Legal Certainty and Legitimacy of State Forest Gazettment in Riau Province, Indonesia)", Jurnal Analisis Kebijakan Kehutanan, Vol. 12 No. 1, April;

Suwitno Y. Imran, 2013, “Fungsi Tata Ruang Dalam Menjaga Kelestarian Lingkungan Hidup Kota Gorontalo", Jurnal Dinamika Hukum Vol. 13 No. 3 September.

\section{Sumber Lain}

Dinas Lingkungan Hidup dan Kehutanan Provinsi Bengkulu, Review Rencana Tata Ruang Wilayah (RTRWP) Bidang Kehutanan, Laporan, Desember 2017;

Steni, Bernadinus, 2016, Membedah UU Pemerintahan Daerah yang Baru: Apa yang Baru dalam Pembagian Urusan dan Kewenangan Pusat--Daerah di Bidang Sumber Daya Alam, Ringkasan Eksekutif, INOBU (Institut Penelitian Inovasi Bumi), Jakarta, hlm. ii. Lihat ttps:// earthinnovation.org/wp-content/uploads/2014/09/INOBU-Report-Membedah -UU-Pemerintahan-Daerah-yang-Baru.pdf., diakses, 9 September 2019;

Transtoto Handadhari, Tata Ruang dan Bencana, Majalah Gatra, tanggal 4 Maret 2016, lihat https://www.atrbpn.go.id/Berita/Berita-Pertanahan/tata-ruang-dan-bencana-alam61881, diakses 8 September 2019. 